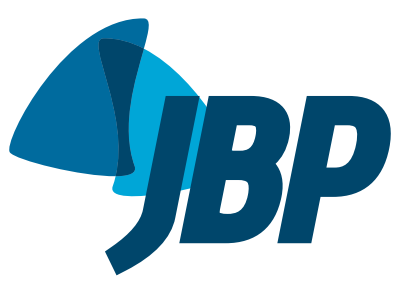

1. Departamento de Enfermagem Universidade Estadual Paulista Júlio de Mesquita Filho - Unesp - Botucatu (SP) Brasil.

2. Departamento de Clínica Médica, Universidade Estadual Paulista Júlio de Mesquita Filho - Unesp - Botucatu (SP) Brasil.

Submitted: 30 April 2015

Accepted: 27 January 2016.

Study carried out at the Universidade Estadual Paulista Júlio de Mesquita Filho Unesp - Botucatu (SP) Brasil.

\section{Psychological distress related to smoking cessation in patients with acute myocardial infarction}

\author{
Thyego Mychell Moreira-Santos ${ }^{1}$, Irma Godoy² ${ }^{2}$ Ilda de Godoy ${ }^{1}$
}

\begin{abstract}
Among all causes of preventable deaths, smoking is responsible for the greatest number of deaths worldwide and predisposes to fatal, noncommunicable diseases, especially cardiovascular diseases. Lifestyle changes are effective in the treatment of patients with smoking-related diseases and assist in the prevention of premature mortality. Our objective was to investigate the available scientific evidence regarding the psychological distress related to smoking cessation in patients who have had acute myocardial infarction. To that end, we conducted an integrative review of the literature in order to summarize relevant studies on this topic. The selected databases were Scopus, PubMed Central, Institute for Scientific Information Web of Science (Core Collection), ScienceDirect, EMBASE, SciELO, LILACS e PsycINFO. On the basis of the inclusion and exclusion criteria adopted for this study, 14 articles were selected for analysis. Those studies showed that the prevalence of psychological distress is higher among smokers than among nonsmokers, and distress-related symptoms are much more common in smokers with acute myocardial infarction than in those without. Smoking cessation depends on the active participation of the smoker, whose major motivation is the underlying disease. Most studies have shown that there is a need to create treatment subgroups as a means of improving the treatment provided. This review article expands the knowledge regarding smoking cessation and shows the need to invest in future research that investigates subgroups of smokers diagnosed with the major smokingrelated comorbidities, such as acute myocardial infarction, in order to develop specific interventions and psychological support strategies.
\end{abstract}

Keywords: Smoking; Stress, psychological; Myocardial infarction; Tobacco use cessation.

\section{INTRODUCTION}

Nicotine is classified as an addictive substance, albeit a licit one. Smoking is a public health problem worldwide, having negative consequences and unfavorable economic implications, as well as being the leading cause of preventable death. ${ }^{(1-3)}$

Exposure to tobacco smoke is a major risk factor for various conditions that predispose to fatal noncommunicable diseases, ${ }^{(4)}$ especially cardiovascular disease, respiratory disorders, and atherosclerosis, as well as cancer and high blood pressure. ${ }^{(5-8)}$ Worldwide, smoking kills one person every six seconds and accounts for one in ten deaths among adults. It is estimated that up to half of current tobacco users will die from a smoking-related disease. ${ }^{(9)}$

Studies show that smokers, compared with nonsmokers, have less knowledge of the social, psychological, and physical issues related to smoking, as well as poorer quality of life, ${ }^{(10,11)}$ smokers living, on average, 10 years less than do nonsmokers. ${ }^{(10)}$ In addition, smokers have a two times higher 10-year risk of cardiovascular events, as well as double the relative risk of acute myocardial infarction (AMI) after 60 years of age. ${ }^{(12,13)}$ Smoking cessation is the most effective lifestyle modification in the treatment of patients with coronary artery disease and is an effective way to prevent many diseases, as well as to avoid premature mortality. ${ }^{(2,5,14)}$ Therefore, it is necessary and important to encourage the use of smoking cessation strategies.

The difficulty that individuals have in quitting smoking and in maintaining smoking abstinence is multifactorial and complex. ${ }^{(15)}$ Complicating factors such as heart disease appear to increase that difficulty. However, a study carried out in several European countries, in which $48 \%$ of the smokers evaluated were successful in quitting smoking, showed that the proportion of individuals in whom smoking cessation interventions were successful was higher among those who had experienced AMI than among those who had no been diagnosed with a smoking-related disease. ${ }^{(16)}$

Because cardiovascular events, such as AMI, are life-threatening, it is essential that individuals at risk for such events change their behavior and lifestyle. Nonadherence to treatment can inhibit patient recovery and increase the chances that AMI will recur. ${ }^{(17)}$ Current research suggests that smoking cessation strategies targeting smokers in general are not always effective, suggesting that there is a need for strategies focused on specific groups. ${ }^{(18)}$ There is also evidence that the intensive behavioral modification programs designed 
for the general population, involving weekly sessions over a three-month period, will not generate sufficient behavioral changes to prompt individuals at risk for cardiovascular events to adopt a healthy lifestyle, ${ }^{(17)}$ making it necessary to develop new technologies with greater specificity for this type of patient.

Smoking cessation is a dynamic process, considered a great personal challenge that requires considerable effort on the part of smokers. ${ }^{(11)}$ In addition to adapting to a new lifestyle, individuals who quit smoking have to overcome the effects of nicotine withdrawal, which has been linked to cognitive and emotional dysfunction. ${ }^{(19)}$ Some studies have shown that psychological distress is an important factor in the smoking cessation process and should be taken into account in individuals who attempt to quit smoking. The rates of psychological distress are known to be higher among smokers than among nonsmokers. ${ }^{(20)}$ Within this context, the psychological symptoms that are the most common and most widely studied in this group of patients are anxiety and depression. ${ }^{(21,22)}$

Symptoms of anxiety and depression are often aggravated by the relationship between smoking cessation and the sequelae of AMI, which makes smoking abstinence more difficult and underscores the need to improve the methods employed in helping AMI patients quit smoking. Because the role that psychological stress plays in such patients remains unclear, there is a need for studies investigating psychological distress during smoking cessation, especially among patients with heart disease and AMI in particular. Such studies could increase the effectiveness of smoking control measures targeting this population.

\section{METHODS}

This was an integrative review of the literature regarding psychological distress related to smoking cessation in patients who have had AMI. In this review, we synthesize and analyze the relevant studies published on the subject, summarizing previous research.

In this integrative review, we followed the steps proposed by Ganong(23): identification of the theme and formulation of the research question; establishment of the purpose of the review; establishment of the inclusion and exclusion criteria for selecting the articles in the sample; definition of the information to be extracted from the selected articles; assessment of the studies included; and presentation and interpretation of the results. Two questions guided this review: "What effects does smoking cessation have in individuals who have suffered AMI?"; and "What role does psychological distress play in the smoking cessation process in such individuals?"

For searches of Latin-American databases, we used the following terms, taken from the MeSH browser and from its Portuguese-language counterpart (the DeCS platform): "tobacco" (tabaco), "tobacco use cessation" (abandono do uso de tabaco), "myocardial infarction" (infarto do miocárdio), and "stress, psychological" (estresse psicológico). The descriptors in English and Portuguese were combined by means of the Boolean operators "AND" and "OR". Entry terms (synonyms) listed in the MeSH (and DeCS) records were used for an extended search.

The search for articles was conducted between June and September of 2014. We searched the following databases: Scopus, PubMed Central, Institute for Scientific Information Web of Science, ScienceDirect, EMBASE, SciELO, LILACS, and PsycINFO. Applying the criteria described below, we selected only full studies dealing with the psychological effects of smoking cessation after AMI. We chose to use those databases because they include studies that meet the study inclusion criteria and because we were attempting to encompass all relevant studies that dealt with the theme under study.

In selecting articles, we applied the following inclusion criteria: being an original article; involving human subjects over 18 years of age; having been published in a journal indexed for at least one of the eight databases searched; having its abstract and full text freely available online; having been published between 1990 and 2014; having been published in Portuguese, Spanish, or English; and dealing with smoking cessation, psychological distress, heart disease, and AMI. Our searches were not limited by the gender of the study subjects. We excluded articles that did not deal with the theme under study, as well as those for which the full text was not available in digital form, and those that were not original articles, such as editorials, conference proceedings, working papers, case reports, and review articles.

For the purposes of this review, we developed a specific data collection tool. By using that tool, we were able for collect information in a way that facilitated the description, organization, and interpretation of the results.

\section{RESULTS}

We identified 1,040 articles, 252 of which were duplicates. On the basis of the titles alone, we excluded 564 articles, and 5 of the articles selected were found to be unavailable. The remaining 219 articles were evaluated within the context of the proposed study criteria. On the basis of the abstracts, another 92 articles were excluded, the remaining 127 being read in their entirety. After reading the full texts, we selected 14 articles for analysis (Figure 1 ).

Given the singularities of access of the eight analyzed databases, the strategies employed to evaluate the articles were adapted in accordance with the previously established inclusion criteria. The 14 articles selected, each published in a different journal, all dealt with issues related to smoking cessation and psychological distress, and some dealt with those issues within the context of a specific population with heart disease, such as AMI.

Of the 14 articles evaluated, 5 (36\%) were conducted in the United States; 3 (21\%) were conducted in Brazil; 


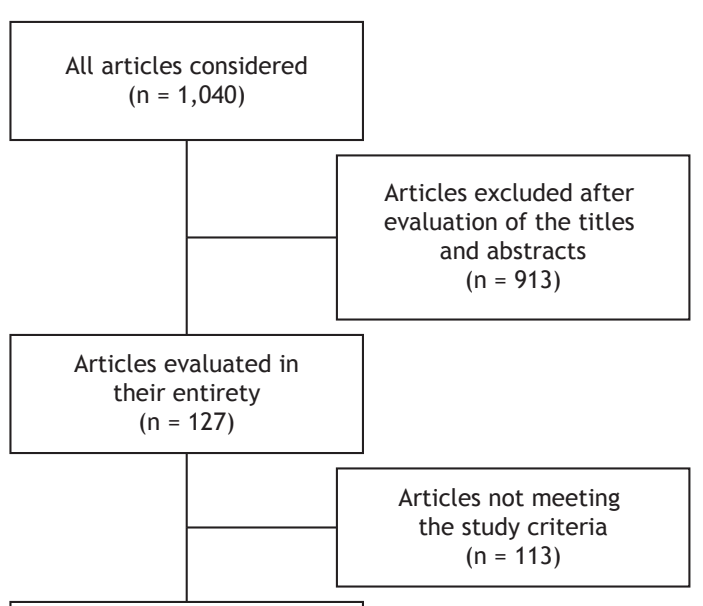

Articles selected and classified as relevant to comprise the study sample $(n=14)$

Figure 1. Flow chart of the article selection process.

$2(14 \%)$ were conducted in Canada; 2 (14\%) were conducted in the United Kingdom; 1 (7\%) was conducted in the Netherlands; and 1 (7\%) was conducted in Italy. Twelve (86\%) of the articles were written in English, and 2 (14\%) were written in Portuguese.

Most of the articles were published between 2009 and 2013 (mode = 5 in 2009). Outliers were articles published in 1990, 1995, and 2002 (1 each year).

All of the selected studies used a quantitative approach, cross-sectional studies accounting for $42 \%$, compared with $14 \%$ each for longitudinal studies and randomized clinical trials. The remaining studies adopted a prospective non-randomized approach (case-control, cohort, retrospective, or double-blind studies).

Seven $(50 \%)$ of the 14 articles selected presented studies conducted in a hospital setting. Four $(28 \%)$ were based on nationwide surveys. Among the articles analyzed, the instrument most often employed was the Fagerström Test for Nicotine Dependence (FTND), which was used in order to detect nicotine dependence among smokers in 5 (35\%) of the studies.

The results of the studies analyzed suggest that people with high levels of psychological distress are more likely to be smokers, given that psychological distress is approximately two times more common among smokers than among nonsmokers. Psychological distress is also associated with a lower probability of smoking cessation and high levels of nicotine dependence, thus increasing the risk of relapse during the first year of follow-up. (24-26)

Some of the studies evaluated showed that smokers and former smokers have depressive symptoms more often than do nonsmokers, and that smokers who use antidepressants are more likely to suffer from anxiety and insomnia. ${ }^{(27-29)}$ The data also suggest that smoking cessation is associated with reduced anxiety and distress. ${ }^{(29,30)}$
In one of studies evaluated, the authors observed that depression decreases the likelihood of smoking cessation and increases the susceptibility to relapse during abstinence. ${ }^{(31)}$ In another of the studies, which investigated a sample of patients with coronary artery disease, the authors reported that depressive symptoms and increased use of antidepressants were more common in smokers than in nonsmokers. ${ }^{(28)}$

In keeping with the objective of this review, some of the studies evaluated showed that AMI is a prevalent heart disease among smokers and that quality of life is poorer among smokers with AMI than among those without. ${ }^{(18,27)}$ Smoking cessation can abruptly expose AMI patients to high levels of psychological stress, and this information is essential for continuous and investigative assessment related to the management of nicotine withdrawal after AMI, given the potential negative impact of psychological stress on physical findings in these patients. ${ }^{(27)}$ The data also indicate that the frequency of a diagnosis of a psychiatric disorder and the level of nicotine dependence are high among AMI patients enrolled in smoking cessation programs. Those factors, combined with the greater stress levels, increase cigarette consumption, which calls for special care, involving cognitive behavioral therapy in order to achieve the best results. ${ }^{(31)}$

Among the studies analyzed, it can be seen that health problems such as AMI and respiratory problems constitute the main motivation to quit smoking. ${ }^{(31,32)}$ Smoking cessation reduces the risk of death after AMI by half, and health professionals play a major role in the smoking cessation process, especially in the guidance and counseling aspects. ${ }^{(32)}$ There is a need for a differentiated approach to this segment of the population (i.e., smokers who have experienced AMI) and therefore to develop interventions focusing on the motivational aspects, in order to engage such individuals in the smoking cessation process. ${ }^{(33)}$

Studies show that cigarette consumption and the level of nicotine dependence both correlate directly with the risk of AMI. This risk can be reduced to levels close to that of nonsmokers when abstinence from smoking is maintained for a period of three to four years, regardless of the previous daily cigarette consumption and smoking history (pack-years), again underscoring the importance of smoking cessation. $(34,35)$ Therefore, smoking cessation efforts should be initiated early, especially in individuals who have been diagnosed with a smoking-related disease. ${ }^{(36)}$

Table 1 summarizes the characteristics of the selected articles. The table shows the specific details of the studies analyzed, including the names of the authors, the year of publication, the country in which the study was conducted, the sample size, and the type of study.

\section{DISCUSSION}

This review highlights the importance of evaluating psychological distress as a way to improve adherence to smoking cessation therapy in patients who have 
had AMI, as well as addressing the importance of such evaluations to strengthening the health care system and to developing new lines of scientific research. Therefore, we believe that there is a need for additional studies investigating the issue addressed here, mainly because we determined that there is a lack of such studies, not only in Brazil but also worldwide.

Among the studies evaluated in this review, there was a variety of methodological approaches, and the articles were published in journals covering various areas of health. That reflects the plurality of the theme studied and shows that many different methods can be employed in investigating this type of issue. There was a predominance of articles published in 2009, which clearly shows the importance that this issue had in that year. However, when we compared the studies in terms of the country of origin, we found no predominance of one country over the others. Therefore, the attention given to investigating psychological distress in patients who have had AMI, during the period evaluated, appears to have been evenly distributed worldwide.

In this review, the country that produced the most scientific research on psychological distress during smoking cessation in patients who have had AMI was the United States, which can be explained by advances in heart research in that country. It is likely that researchers in the United States recognized the importance of conducting pathophysiological studies of cognitive aspects, including psychological distress. That type of approach improves the understanding of the subject by encompassing various aspects and enables the development of strategies aimed at specific subgroups. Another country that produced considerable scientific research on this issue was Brazil. However, among the selected articles conducted in Brazil, there were no specific studies involving individuals with AMI-only studies analyzing the smoking cessation process and the associated psychological distress.
This indicates the need for further studies of this issue in Brazil. Such studies should analyze important behavioral aspects in comparison with existing studies in the literature in order to improve the planning of interventions aimed at promoting health.

The great majority of the studies evaluated in this review were conducted in a hospital setting, reflecting the central position that this type of institution historically occupies in health care systems worldwide. It should be borne in mind that hospitals also play a prominent role within the context of the issue under study here, mainly in terms of the services provided to smokers and to individuals with cardiovascular disease.

The assessment tool most often used in the studies considered in this review was the FTND. The FTND is an important tool in the evaluation of nicotine addiction because it helps determine the smoking history (in pack-years) and the level of patient motivation for smoking cessation. Higher scores on the FTND indicate greater nicotine dependence, which makes it more difficult for the individual to quit smoking.

Most of the studies evaluated in this review had a cross-sectional design, including a description of the characteristics of the study population. Some demonstrated associations between or among variables, although without showing a causal relationship with the object of study, especially because they failed to identify a temporal relationship between the initial exposure to the risk factor and the subsequent development of disease. Therefore, conclusions related to psychological distress as a consequence of smoking cessation should be drawn with caution.

The main limitation of cross-sectional studies is related to the issue of smoking abstinence in relation to psychological distress. The association between those two factors can be influenced by AMI, making it necessary to investigate the development of psychological distress during the smoking cessation process.

Table 1. Articles included in the review.

\begin{tabular}{|c|c|c|c|c|c|}
\hline Authors & Year & Journal & Country of origin & $\mathbf{N}$ & Type of study \\
\hline Figueiró et al. ${ }^{(11)}$ & 2013 & Trends Psychiatry Psychother & Brazil & 54 & Cohort \\
\hline Castro et al. ${ }^{(18)}$ & 2010 & J Bras Pneumol & Brazil & 167 & Cross-sectional \\
\hline Lawrence et al. ${ }^{(24)}$ & 2011 & BMC Public Health & USA & 31,428 & Cross-sectional \\
\hline Cosci et al. ${ }^{(25)}$ & 2009 & Addict Behav & Italy & 297 & $\begin{array}{l}\text { Double-blind, } \\
\text { randomized }\end{array}$ \\
\hline Hajek et al. (26) & 2010 & Addiction & England & 469 & $\begin{array}{c}\text { Randomized clinical } \\
\text { trial }\end{array}$ \\
\hline Pfaff et al. (27) & 2009 & Can J Cardiovasc Nurs & Canada & 57 & Cross-sectional \\
\hline Gravely-Witte et al. ${ }^{(28)}$ & 2009 & J Behav Med & Canada & 1,498 & $\begin{array}{c}\text { Prospective, } \\
\text { non-randomized }\end{array}$ \\
\hline Peiper et al. ${ }^{(29)}$ & 2013 & $\begin{array}{c}\text { Soc Psychiatry Psychiatr } \\
\text { Epidemiol }\end{array}$ & USA & 133,221 & Cross-sectional \\
\hline Cavazos-Rehg et al. ${ }^{(30)}$ & 2014 & Psychol Med & USA & 4,853 & Longitudinal \\
\hline Aguiar et al. ${ }^{(31)}$ & 2009 & Rev Port Pneumol & Brazil & 567 & Retrospective analysis \\
\hline Greenwood et al. ${ }^{(32)}$ & 1995 & J Epidemiol Community Health & UK & 1,283 & Cross-sectional \\
\hline Sachs-Ericsson et al. ${ }^{(33)}$ & 2009 & Nicotine Tob Res & USA & 4,162 & Cross-sectional \\
\hline Rosenberg et al. ${ }^{(34)}$ & 1990 & N Engl J Med & USA & 3,285 & Case-control \\
\hline Pedersen et al. ${ }^{(36)}$ & 2002 & Neth Heart J & The Netherlands & 28 & Longitudinal \\
\hline
\end{tabular}


In other words, the exposure and the outcome of the phenomenon should be studied at different times. Other important factors in the analysis relate to the period of investigation and the duration of psychological distress. To address these key points and to minimize the limitations, we suggest conducting longitudinal studies in which there is an analysis of various time points or periods during the therapeutic process of smoking cessation. Such an approach would provide more accurate evidence of the relationship between the studied factors and the variables of interest.

On the basis of the findings of the studies sampled here, we can conclude that smokers with AMI have greater difficulty in quitting smoking because of their greater propensity to experience psychological distress during the smoking cessation process. Some of the authors showed that quitting smoking rapidly and without preparation by health professionals increases psychological distress, including symptoms related to anxiety and depression, which contributes to the increasing rates of smoking cessation treatment failure in this subgroup of smokers.

In view of the results of the studies sampled here, we can state that smoking cessation treatment failure is linked to the inability of health professionals responsible for treatment to evaluate and guide their patients through the smoking cessation process. In addition, there is the lack of preparation to diagnose psychological distress and to create coping strategies to deal with particular themes, strategies which would ideally be focused on the difficulties encountered by individuals with nicotine dependence and smoking-related diseases, such as AMI. One study showed that the role of the health professional is focused on the importance of developing interventions that are more targeted to specific populations, as well as addressing the differences between men and women. ${ }^{(37)}$

The literature suggests that, among health professionals, pulmonologists having great potential to promote a reduction of smoking. However, most pulmonologists in Brazil do not consider smoking a medical condition, as evidenced in a survey conducted in Brazil, in which only $35.3 \%$ of the pulmonologists surveyed reporting offering the correct smoking cessation regimen-the combination of cognitive behavioral therapy and pharmacological treatment. (38) Another factor that is worrisome is that most of those professionals showed disinterest in the subject, reported not having time to counsel their smoking patients, or did not even know how to combat smoking. ${ }^{(38)}$

It is very important that health professionals be committed to smoking cessation programs. Training is essential to improve knowledge, particularly in relation to supporting patients during the smoking cessation process. ${ }^{(39)}$ Therefore, developing strategies that fit the profile of each patient is critical to facilitating the search for known predictors of treatment failure, such as psychological distress. ${ }^{(40)}$ All smoking patients should be evaluated in terms of the degree of nicotine dependence and the level of motivation to quit smoking. ${ }^{(41)}$
Psychological distress should be an important issue in the management of smoking patients, particularly by professionals responsible for smoking cessation programs. According to one of the articles included in this review, psychological distress predisposes the smoker to greater dependence, greater difficulty in quitting smoking, and an increased risk of relapse during treatment or after discharge from the program. ${ }^{(31)}$ Therefore, interventions for smoking control should consider the general characteristics of smokers in order for smoking cessation treatment to be effective. ${ }^{(42)}$ Health professionals should also consider the smoking history of patients enrolled in such programs, in order to improve and individualize practices related to their treatment. ${ }^{(41)}$ With such approaches, clinical evaluations are necessary during smoking cessation therapy, and instruments to analyze the personality and psychological distress of the participants should be employed as a way of developing specific strategies, such as psychological support interventions, for use in subgroups of smokers. ${ }^{(25)}$ The results of this review show that such strategies can increase adherence to treatment and help patients cope with their symptoms, especially during smoking abstinence.

Among the symptoms of psychological distress, depression and anxiety have been the most widely researched. Data in the literature indicate that smoking has a direct bearing on the development of those symptoms, which are also elements responsible for the high relapse rates, making smoking cessation difficult. Our results also show that depression and anxiety are more common in subgroups of smokers, such as those with AMI, underscoring the greater propensity of such smokers to experience psychological distress. That finding could be linked to the clinical picture of the patient with AMI, together with the apprehension factor with respect to fear, because the condition involves the possibility of recurrence and is associated with high mortality. However, one recent study showed that smoking cessation treatment reduces levels of anxiety and depression, as well as increasing motivation and reducing stress. Those changes appear to be more pronounced in patients in whom the treatment was successful. ${ }^{(43)}$ Therefore, in smokers with depression, the intensity of the depressive symptoms should be evaluated before and during the intervention, in order to identify the patients who present a higher risk of relapse. ${ }^{(41)}$

Nicotine dependence and smoking-related diseases should be taken into consideration in the context of smoking cessation treatment, mainly because most smokers present particular and specific characteristics that require special attention, which makes it important to identify specific subgroups of patients, such as those with AMI. Therefore, a thorough evaluation of the patient seeking treatment is of fundamental importance to optimizing the various treatment strategies, which should take into account psychiatric disorders such as anxiety and depression. This corroborates the findings 
of a study demonstrating that those symptoms are factors that hinder patient adherence to treatment. ${ }^{(44)}$

The type of treatment also has an influence on smoking cessation. One study showed that certain pharmacological therapies, such as nicotine replacement, can increase the occurrence of depressive episodes. ${ }^{(45)}$ In such cases, the drug of choice should be bupropion, because it has been proven to be an effective antidepressant for use in smoking cessation treatment. However, self-administered pharmacological therapy alone has proven insufficient to achieve smoking cessation, making it important to combine it with cognitive behavioral therapy. Cognitive behavioral therapy involves the active participation of the patient. In the case of patients in smoking cessation treatment programs, that means that the patients themselves identify routine risk situations and, together with a health professional, develop coping strategies to deal with these situations. ${ }^{(46)}$ Cognitive behavioral therapy techniques also help smokers modify the pattern of conduct in their cigarette consumption, avoiding situations linked to recidivism. That involves learning how to resist the urge to smoke and adopting strategies to counter the smoking habit. ${ }^{(41)}$

Most of the articles included in this review highlight the importance of smoking prevention and smoking cessation programs, which should be initiated early in order to reduce the risk of developing major diseases related to smoking, such as AMI, as well as to improve the health of patients already affected by such diseases. One of the selected articles discusses the importance of intersectoral cooperation and the referral/back-referral system as ancillary tools in the attempt to quit smoking. ${ }^{(36)}$ According to the authors of that study, the health system is only effective when the responsibility is shared by all sectors. In other words, nicotine-dependent individuals, with or without smoking-related diseases, should be initially evaluated in the hospital and subsequently referred to group therapy, where they are counseled and monitored by qualified professionals, who tailor the treatment to each specific case. ${ }^{(36)}$ Thus, the health system could increase the effectiveness of smoking control measures, giving more coverage to the population and providing effective, high-quality care.

This integrative review shows that smoking cessation is a dynamic process and requires the active participation of smokers, whose motivation influences the smoking cessation process. Studies show that psychological distress is directly related to nicotine dependence, which increases the difficulty of smoking cessation, as well as increasing the incidence of depression. The success of smoking cessation treatment is linked to adherence to cognitive behavioral therapy and pharmacological therapy, given that health problems, AMI and respiratory problems in particular, constitute the main motivation to quit smoking. However, quitting smoking rapidly and without appropriate preparation increases psychological stress in patients with AMI, making it difficult to maintain smoking abstinence. Treatment failure is linked to the unpreparedness on the part of health professionals responsible for monitoring such patients to diagnose psychological distress, as well as to a lack of specific treatment subgroups created in order to address and deal with particular themes, such as AMI.

This review expands the knowledge on the subject of smoking cessation and psychological distress in AMI patients, showing the need to invest in further research to analyze subgroups of smokers with major smoking-related diseases, in order to develop specific interventions with psychological support. The attention given to the role played by such diseases could be an interesting line of research, in order to improve treatment adherence in specific treatment subgroups and increase smoking cessation rates, which are considered low in comparison with those of the desire to quit smoking. This type of approach would also improve the knowledge of health professionals about dealing with nicotine dependence and thus improve planning, with broader approaches, treatments that are more effective, and a greater number of intervention strategies.

\section{REFERENCES}

1. Seabra CR, Faria HM, Santos FR. O tabagismo em uma perspectiva biopsicossocial: panorama atual e intervenções interdisciplinares. CES Revista [serial on the Internet] 2011(25)321-36. Available from: http://www.cesjf.br/revistas/cesrevista/edicoes/2011/21_ PSICOLOGIA_Tabagismo.pdf

2. World Health Organization. Global health risks: mortality and burden of disease attributable to selected major risks. Geneva: WHO; 2013.

3. Fagundes LG, Martins MG, Magalhães EM, Palmiéri PC, Silva SI Jr. Health policies for tobacco control in Latin America and the Caribbean: an integrative review [Article in Portuguese]. Cienc Saude Coletiva. 2014;19(2):499-510. http://dx.doi.org/10.1590/1413 81232014192.13482012

4. Health Canada [homepage on the Internet]. Ottawa: Health Canada [updated 2014 May 16, cited 2015 Apr 1]. Sleeping with A killer: a report from Health Canada's tobacco control programme. Available from: http://www.hc-sc.gc.ca/hl-vs/pubs/tobac-tabac/swk-dat/ intro01-eng.php

5. World Health Organization. WHO Report on the Global Tobacco Epidemic 2008: the MPOWER package. Geneva: World Health Organization; 2008.

6. Punturieri A, Szabo E, Croxton TL, Shapiro SD, Dubinett SM Lung cancer and chronic obstructive pulmonary disease: needs and opportunities for integrated research. J Natl Cancer Inst. 2009;101 (8):554-9. http://dx.doi.org/10.1093/jnci/djp023

7. World Health Organization. Global health risks: mortality and burden of disease attributable to selected major risks. Geneva: WHO; 2009

8. Centers for Disease Control and Prevention (CDC). State specific smoking-attributable mortality and years of potential life lost-United States, 2000-2004. MMWR Morb Mortal Wkly Rep 2009;58(2):29-33.

9. World Health Organization. Report on the global tobacco epidemic Geneva: WHO; 2013

10. Doll R, Peto J, Borehan J, Sutherland I. Mortality in relation to smoking: 50 years' observations on male British doctors. BMJ. 2004;328(7455):1519. http://dx.doi.org/10.1136/bmj.38142.554479. $\mathrm{AE}$

11. Figueiró LR, Bortolon CB, Benchaya MC, Bisch NK, Ferigolo $M$ Barros HM, et al. Assessment of changes in nicotine dependence, motivation, and symptoms of anxiety and depression among smokers in the initial process of smoking reduction or cessation: a short-term 
follow-up study. Trends Psychiatry Psychother. 2013;35(3):212-20 http://dx.doi.org/10.1590/S2237-60892013000300008

12. Edwards R. The problem of tobacco smoking. BMJ. 2004;328(7433):217-9. http://dx.doi.org/10.1136/bmi.328.7433.217

13. Bruijnzeel AW. Tobacco addiction and the dysregulation of brain stress systems. Neurosci Biobehav Rev. 2012;36(5):1418-41. http:// dx.doi.org/10.1016/j.neubiorev.2012.02.015

14. Spatola CA, Manzoni GM, Castelnuovo G, Malfatto G, Facchini M, Goodwin $\mathrm{CL}$, et al. The ACTonHEART study: rationale and design of a randomized controlled clinical trial comparing a brief intervention based on Acceptance and Commitment Therapy to usual secondary prevention care of coronary heart disease. Health Qual Life Outcomes. 2014;12:22. http://dx.doi.org/10.1186/1477-7525-12-22

15. Carvalho AA, Gomes L, Loureiro AL, Bezerra AJ. Controle do tabagismo em instituição de longa permanência para idosos: relato de experiência. Cienc Saude Coletiva. 2013;18(4):1119-30. http:// dx.doi.org/10.1590/S1413-81232013000400025

16. Twardella $D$, Loew $M$, Rothenbacher $D$, Stegmaier $C$, Ziegler $H$, Brenner $H$. The diagnosis of a smoking-related disease is a prominent trigger for smoking cessation in a retrospective cohort study. J. Clin Epidemiol. 2006;59(1):82-9. http://dx.doi.org/10.1016/j. jclinepi.2005.05.003

17. Johnston DW. Lifestyle changes after a myocardial infarction. Heart. 1999;82(5):543-4. http://dx.doi.org/10.1136/hrt.82.5.543

18. Castro MR, Matsuo T, Nunes SO. Clinical characteristics and quality of life of smokers at a referral center for smoking cessation. J Bras Pneumol. 2010;36(1):67-74. http://dx.doi.org/10.1590/S180637132010000100012

19. Hughes JR, Keely J, Naud S. Shape of the relapse curve and long-term abstinence among untreated smokers. Addiction. 2004;99(1):29-38. http://dx.doi.org/10.1111/.1360-0443.2004.00540.x

20. Hughes JR, Brandon TH. A softer view of hardening. Nicotine Tob Res. 2003;5(6):961-2. http://dx.doi.org/10.1080/1462220031000161 5330

21. Honda K. Psychosocial correlates of smoking cessation among elderly ever-smokers in the United States. Addict Behav. 2005:30(2):375381. http://dx.doi.org/10.1016/j.addbeh.2004.05.009

22. Lam TH, Li ZB, Ho SY, Chan WM, Ho KS, Li MP, et al. Smoking and depressive symptoms in Chinese elderly in Hong Kong. Acta Psychiatr Scand. 2004;110(3):195-200. http://dx.doi.org/10.1111/ j.1600-0447.2004.00342.x

23. Ganong LH. Integrative reviews of nursing research. Res Nurs Health. 1987;10(1):1-11. http://dx.doi.org/10.1002/nur.4770100103

24. Lawrence D, Mitrou F, Zubrick SR. Non-specific psychological distress, smoking status and smoking cessation: United States National Health Interview Survey 2005. BMC Public Health. 2011;11:256. http://dx.doi.org/10.1186/1471-2458-11-256

25. Cosci F, Corlando A, Fornai E, Pistelli F, Paoletti P, Carrozzi L. Nicotine dependence, psychological distress and personality traits as possible predictors of smoking cessation. Results of a double-blind study with nicotine patch. Addict Behav. 2009;34(1):28-35. http:// dx.doi.org/10.1016/j.addbeh.2008.08.003

26. Hajek $P$, Taylor $T$, McRobbie $H$. The effect of stopping smoking on perceived stress levels. Addiction. 2010;105(8):1466-71. http:// dx.doi.org/10.1111/j.1360-0443.2010.02979.x

27. Pfaff KA, El-Mascri MM, Fox-Wasylyshyn SM. Comparing the psychological stress between non-smoking patients and smoking patients who experience abrupt smoking cessation during hospitalization for acute myocardial infarction: a pilot study. Can J Cardiovasc Nurs. 2009;19(4):26-32.

28. Gravely-Witte S, Stewart DE, Suskin N, Grace SL. The association among depressive symptoms, smoking status and antidepressant use in cardiac outpatients. J Behav Med. 2009;32(5):478-90. http:// dx.doi.org/10.1007/s10865-009-9218-3

29. Peiper N, Rodu B. Evidence of sex differences in the relationship between current tobacco use and past-year serious psychological distress: 2005-2008 National Survey on Drug Use and Health. Soc
Psychiatry Psychiatr Epidemiol. 2013;48(8):1261-71. http://dx.doi. org/10.1007/s00127-012-0644-0

30. Cavazos-Rehg PA, Breslau N, Hatsukami D, Krauss MJ, Spitznagel EL, Grucza RA. Smoking cessation is associated with lower rates of mood anxiety and alcohol use disorders. Psychol Med. 2014;44(12):252335. http://dx.doi.org/10.1017/S0033291713003206

31. Aguiar M, Todo-Bom F, Felizardo M, Macedo R, Caeiro F, SottoMayor $\mathrm{R}$, et al. Four years' follow up at a smoking cessation clinic Rev Port Pneumol. 2009;15(2):179-97. http://dx.doi.org/10.1016/ S0873-2159(15)30126-4

32. Greenwood DC, Muir KR, Packham CJ, Madeley RJ. Stress, socia support, and stopping smoking after myocardial infarction in England. J Epidemiol Community Health. 1995;49(6):583-7. http://dx.doi. org/10.1136/jech.49.6.583

33. Sachs-Ericsson N, Schmidt NB, Zvolensky MJ, Mitchell M, Collins $\mathrm{N}$, Blazer DG. Smoking cessation behavior in older adults by race and gender: the role of health problems and psychological distress. Nicotine Tob Res. 2009;11(4):433-43. http://dx.doi.org/10.1093/ntr/ ntp002

34. Rosenberg L Palmer JR, Shapiro $S$. Decline in the risk of myocardial infarction among women who stop smoking. N Engl J Med. 1990;322(4):213-7. http://dx.doi.org/10.1056/ NEJM199001253220401

35. Araújo AJ, Menezes AM, Dórea AJ, Torres BS, Viegas CA Silvia CA, et al. Diretrizes para Cessação do Tabagismo. J Bras Pneumol. 2004;30(Suppl 2):1-76. http://dx.doi.org/10.1590/S180637132004000800002

36. Pedersen SS, Deckers JW, van Os F, Erdman RA. A multifactorial smoking cessation programme for patients with coronary artery disease: experiences and preliminary results. Neth Heart $J$. 2002;10(2):48-53.

37. Russo AC, Azevedo RC. Factors that motivate smokers to seek outpatient smoking cessation treatment at a university general hospital. J Bras Pneumol. 2010;36(5):603-11.

38. Viegas CA, Valentim AG, Amoras JA, Nascimento EJ. Attitudes of Brazilian pulmonologists toward nicotine dependence: a national survey J Bras Pneumol. 2010;36(2):239-42.

39. Zhu $W H$, Yang $L$, Jiang $C Q$, Deng LZ, Lam TH, Zhang JY, et al. Characteristics of smokers and predictors of quitting in a smoking cessation clinic in Guangzhou, China. J Public Health (Oxf). 2010;32(2):267-76. http://dx.doi.org/10.1093/pubmed/fdp107

40. Santos SR, Gonçalves MS, Leitão Filho FS, Jardim JR. Profile of smokers seeking a smoking cessation program. J Bras Pneumol. 2008;34(9):695-701.

41. Reichert J, Araújo AJ, Gonçalves CM, Godoy I, Chatkin JM, Sales MP, et al. Smoking cessation guidelines-2008. J Bras Pneumol. 2008:34(10):845-80. Erratum in: J Bras Pneumol. 2008;34(12):1090. http://dx.doi.org/10.1590/S1806-37132008001000014

42. Caram LM, Ferrari R, Tanni SE, Coelho LS, Godoy Id, Martin Rdos $\mathrm{S}$, et al. Characteristics of smokers enrolled in a public smoking cessation program. J Bras Pneumol. 2009;35(10):980-5. http://dx.doi. org/10.1590/S1806-37132009001000006

43. Pawlina MM, Rondina RC, Espinosa MM, Botelho C. Depression, anxiety, stress, and motivation over the course of smoking cessation treatment. J Bras Pneumol. 2015;41(5):433-9. http://dx.doi. org/10.1590/S1806-37132015000004527

44. Melo WV, Oliveira MS, Ferreira EA. Estágios motivacionais, sintomas de ansiedade e de depressão no tratamento do tabagismo. Interacão em Psicologia, 2006,10(1):91-9. http://dx.doi.org/10.5380/psi. v10i1.5769

45. Tsoh JY, Humfleet GL, Muñoz RF, Reus VI, Hartz DT, Hall SM, Development of major depression after treatment for smoking cessation. Am J Psychiatry. 2000;157(3):368-74. http://dx.doi. org/10.1176/appi.ajp.157.3.368

46. Presman S, Carneiro E, Gigliotti A. Tratamentos não-farmacológicos para o tabagismo. Rev Psiq Clin. 2005;32(5):267-75. http://dx.doi. org/10.1590/S0101-60832005000500004 